\title{
Extended myectomy for apical hypertrophic cardiomyopathy: a case report
}

\author{
Daiki Saitoh ${ }^{1 *}$, Mike Saji $^{2}$ and Schuichiro Takanashi ${ }^{1}$
}

\begin{abstract}
Background: Apical hypertrophic cardiomyopathy is a variant of hypertrophic cardiomyopathy that predominantly affects the apex of the left ventricle and rarely involves the right ventricular apex or both apexes. Heart transplantation is the traditional treatment for apical hypertrophic cardiomyopathy. Although surgical myectomy approaching the apex has been available for decades, its safety and accuracy greatly depend on the surgeon's skills and experience.

Case presentation: The first case involved a 63-year-old man with apical hypertrophic cardiomyopathy, wherein preoperative contrast computed tomography findings revealed apical hypertrophy and complete apical cavity obliteration. The patient underwent extended myectomy, which revealed the apex cavity filled with abnormal muscles. Using the transaortic approach, the location of the bilateral papillary muscle was confirmed, thereby providing the required orientation. The abnormal muscle mass was successfully resected, and the postoperative end-diastolic volume was extremely increased. The second case involved a 43 -year-old man with an apical left ventricular aneurysm and mid-hypertrophic cardiomyopathy obstruction. The thin-walled apical aneurysm contained a large apical-basal band. Upon detecting the bilateral papillary muscle, mid-ventricular myectomy was performed from the apex. During postoperative catheterization, there was no pressure gradient between the left ventricle and aorta.

Conclusions: We reviewed two cases of apical hypertrophic cardiomyopathy, efficiently treated using extended apical myectomy. Although it is an uncommon procedure, the cases presented show how it can be used to successfully manage cases of apical hypertrophic cardiomyopathy. However, it is important to secure the postoperative left ventricular end-diastolic volume.
\end{abstract}

Keywords: Apical hypertrophic cardiomyopathy, Myectomy, Apical myectomy, Left ventricular end-diastolic volume, Apical cavity obliteration

\section{Background}

Apical hypertrophic cardiomyopathy (aHCM) is a variant of HCM first described in 1976. It predominantly affects the left ventricular apex and rarely involves the right ventricular apex or both apexes. Furthermore, aHCM presents unique echocardiographic findings of asymmetrical apical hypertrophy in an ace-of-spades configuration [1, 2]. Approximately $40 \%$ of $\mathrm{HCM}$ cases involve aHCM.

*Correspondence: daikikouji19@yahoo.co.jp

${ }^{1}$ Department of Cardiovascular Surgery, Sakakibara Heart Institute, Tokyo, Japan

Full list of author information is available at the end of the article
The condition is relatively uncommon in western countries and occurs more frequently in Asian populations [3-7]. aHCM is traditionally treated using heart transplantation. Surgical myectomy approaching the apex (apical myectomy) has been available for decades [8]; however, its safety and accuracy greatly depend on the surgeon's skills and experience [9]. Herein, we report two cases of patients with aHCM who underwent extended myectomy. original author(s) and the source, provide a link to the Creative Commons licence, and indicate if changes were made. The images or other third party material in this article are included in the article's Creative Commons licence, unless indicated otherwise in a credit line to the material. If material is not included in the article's Creative Commons licence and your intended use is not permitted by statutory regulation or exceeds the permitted use, you will need to obtain permission directly from the copyright holder. To view a copy of this licence, visit http://creativecommons.org/licenses/by/4.0/. The Creative Commons Public Domain Dedication waiver (http://creativeco mmons.org/publicdomain/zero/1.0/) applies to the data made available in this article, unless otherwise stated in a credit line to the data. 


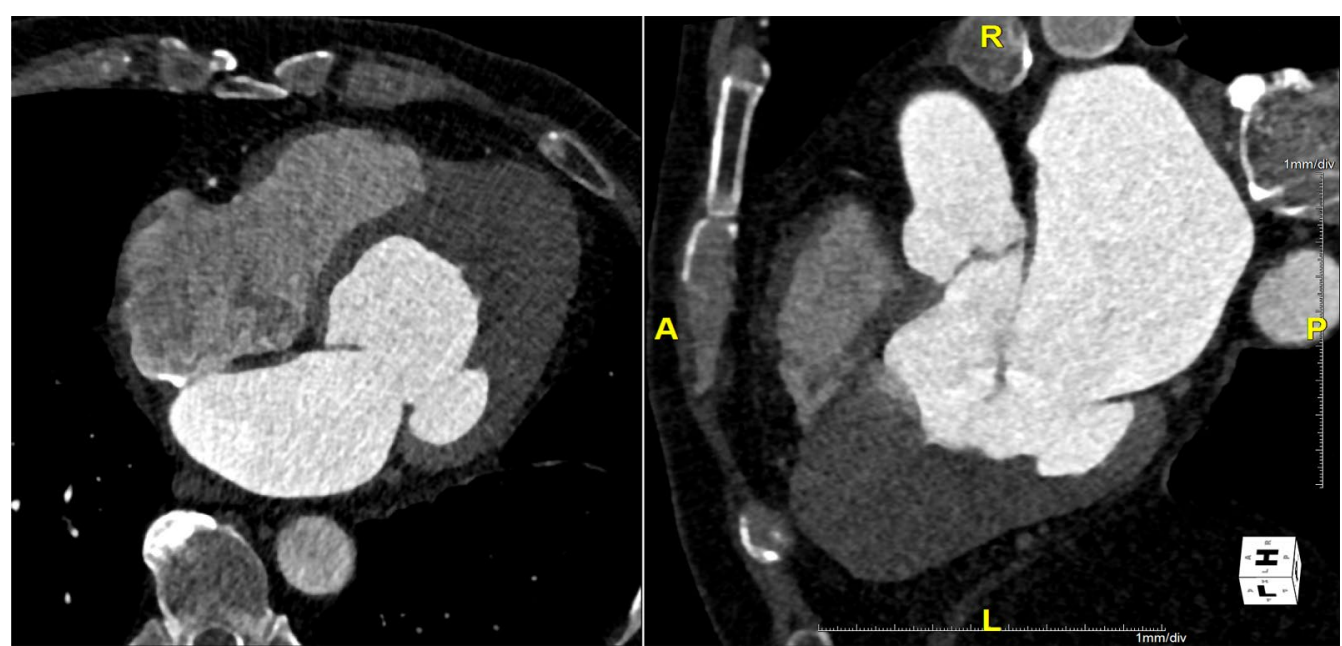

Fig. 1 Preoperative CT images from Case 1. CT, computed tomography

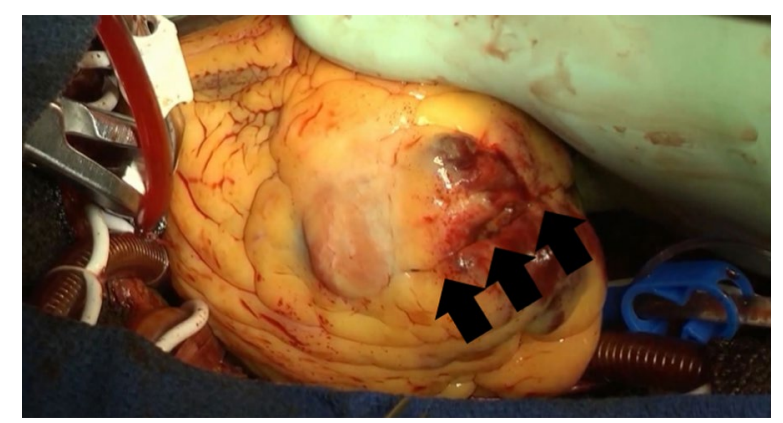

Fig. 2 Intraoperative finding shows the incision line of the apex

\section{Case presentation}

\section{Case 1}

A 63-year-old man with an 8-year history of aHCM had remained healthy for 7 years until he was diagnosed with aHCM, during which he began to experience exertional dyspnea. He was referred to our hospital for surgical aHCM treatment. Preoperative contrast computed tomography (CT) revealed apical hypertrophy and complete apical cavity obliteration. Preoperative transesophageal echocardiography (TEE) revealed no systolic anterior motion (SAM) and an abnormal apical-basal band.

The patient underwent extended myectomy, which revealed the apex cavity filled with abnormal muscles (Fig. 1). Therefore, we could not decide on the orientation for making an incision on the myocardium. The ventriculotomy line was created lateral and parallel to the left anterior descending artery. The incision line was over the apex, with a length of approximately 5-10 cm (Fig. 2). The cell saver sucker and cardiac sucker were used to retract the papillary muscles;

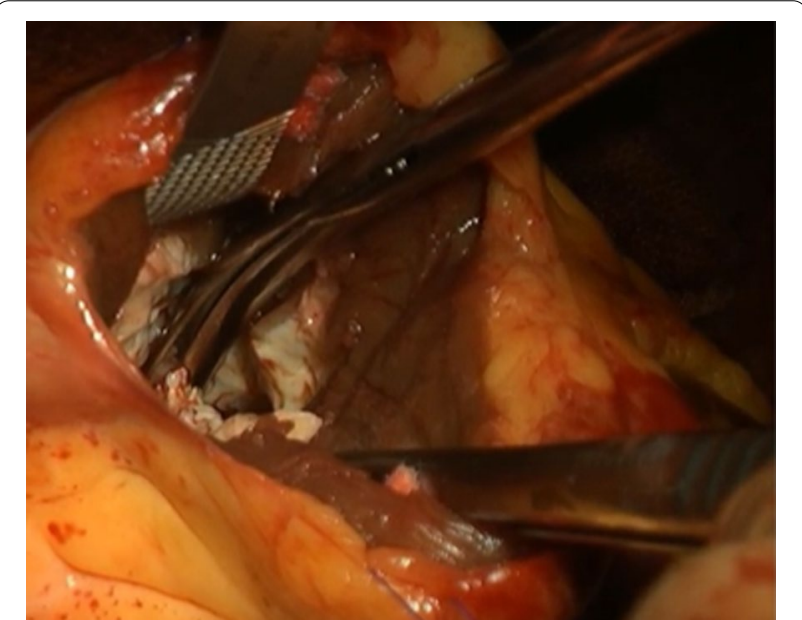

Fig. 3 Intraoperative finding shows white fibrous endocardial muscles

consequently, additional incisions were made. When white fibrous endocardial muscles were identified, we used two 4-0 pledget monofilament sutures to retract the left ventricular (LV) wall on each side (Fig. 3). Excess hypertrophic muscles on the LV free wall and abnormal papillary muscles were shaved (Fig. 4). Using the transaortic approach, we confirmed the location of the bilateral papillary muscle, which indicated the required orientation. Initially, a bidirectional tunnel approach was performed between the bilateral papillary muscle and resected area to avoid the apex. We used 2-0 monofilament sutures for LV closure. The cardiopulmonary bypass time was $148 \mathrm{~min}$, and the aortic clamp was on for $93 \mathrm{~min}$. 


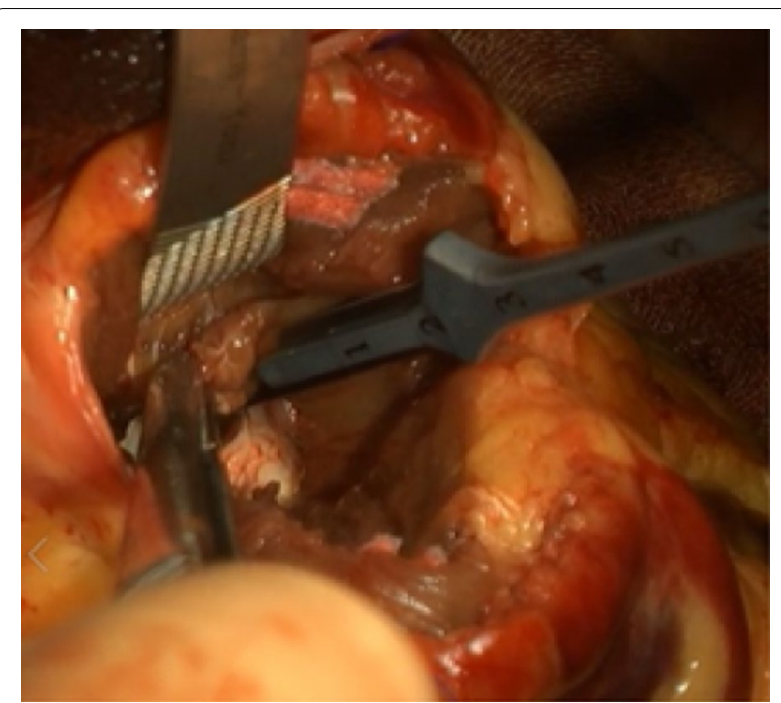

Fig. 4 Intraoperative finding shows excess hypertrophic muscles on the LV free wall and abnormal papillary muscles are shaved. LV, left ventricular

Postoperative contrast CT findings showed a small LV aneurysm, which was surgically resected 3 weeks after the initial myectomy. On postoperative day 3, the patient developed septic shock because of urinary tract infection and mediastinitis. After antibiotic administration and omentopexy, he was transferred to his previous hospital where he underwent 90 days of rehabilitation. Postoperative TEE demonstrated an LV end-diastolic volume (LVEDV)/end-systolic volume of 105.3/56.5 mL (preoperative, 67.2/35.9 mL). Postoperative left ventriculogram and angiography findings are presented in Fig. 5. The patient's exertional dyspnea improved, and he was discharged 30 days after being transferred to the referring hospital.

\section{Case 2}

A 43-year-old man with an apical LV aneurysm and mid-HCM obstruction was referred to our hospital for further evaluation. Eight years earlier, he was fitted with an implantable cardioverter-defibrillator (ICD) for non-sustained ventricular tachycardia. Mid-HCM was detected using $\mathrm{CT}$ and transthoracic echocardiography (TTE), and he was followed up as an outpatient for 5 years. One month before presenting at our hospital, he developed syncope and palpitations.

Preoperative contrast CT findings revealed an apical aneurysm and mid-ventricular obstruction. Preoperative TEE revealed mid-acceleration but no SAM. He underwent extended myectomy to alleviate palpitations and arrhythmia. A large apical-basal band was located inside the thin-walled apical aneurysm. Mid-ventricular myectomy was performed from the apex after detecting the bilateral papillary muscle. The resected myocardium weighed $9 \mathrm{~g}$. The aneurysm was removed, and the incision was closed. Cardiopulmonary bypass lasted for $85 \mathrm{~min}$, and the aorta was clamped for $50 \mathrm{~min}$. Postoperative TEE findings revealed no SAM or ventricular septal perforation. During postoperative catheterization, there was no pressure gradient between the left ventricle and aorta.

On postoperative day 8 , the patient exhibited atrial flutter, and defibrillation was performed via an ICD, which restored sinus rhythm. He was discharged on postoperative day 10.

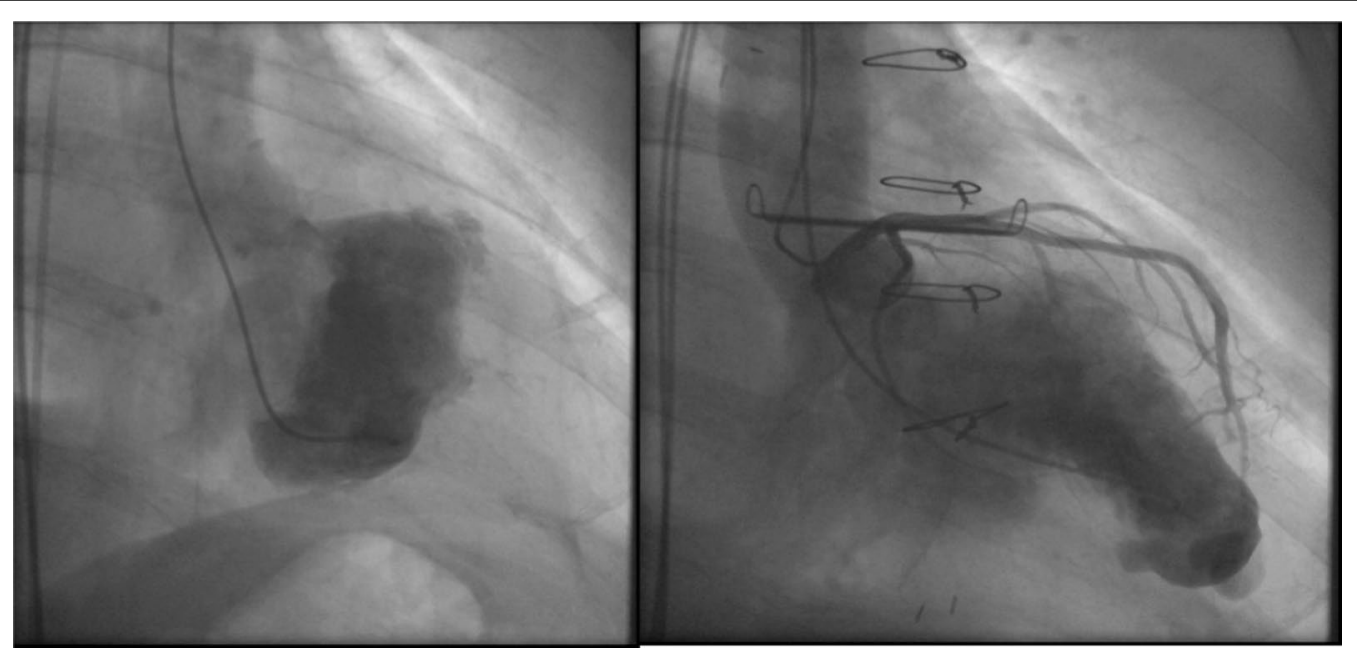

Fig. 5 Pre- and postoperative cardiography images from Case 1 
Table 1 Comparison of the two aHCM and LVOTO cases

\begin{tabular}{|c|c|c|}
\hline & aHCM & LVOTO \\
\hline Cause of decreasing SV & LVDEV $\downarrow$ & LVOTS, SAM \\
\hline Difficulties of procedure & Invisible & More visible \\
\hline Surgical complications & $\begin{array}{l}\text { Mitral valve injury, ventricular septal perforation, left coronary } \\
\text { injury }\end{array}$ & $\begin{array}{l}\text { Aortic valve injury, } \\
\text { ventricular septal } \\
\text { perforation }\end{array}$ \\
\hline
\end{tabular}

aHCM, apical hypertrophic cardiomyopathy; LVEDV, left ventricular end-diastolic volume; LVOTO, left ventricular outflow tract obstruction; LVOTS, left ventricular outflow tract stenosis; SAM, systolic anterior motion; SV, stroke volume

\section{Discussion and conclusions}

LV septal myectomy is the gold standard surgical treatment for LV outflow tract obstruction (LVOTO) in patients with HCM [10]. However, the safety and accuracy of apical myectomy depend on the surgeon's skills and experience [9], as it is an uncommon procedure. Apical myectomy can be used for aHCM repair; however, postoperative LVEDV should be secured. Postoperatively, cardiac output likely improves because of increased outflow area and reduced drag forces on the anterior mitral leaflet (AML) by changing the flow vector in the outflow tract, which is more parallel to the AML.

The patient from Case 1 had extensive hypertrophy, especially in the apex; therefore, we could not perform myectomy using only the transaortic approach. However, using both apex and transaortic approaches, we were able to determine the positions of the bilateral papillary muscles, chordates, and mitral valve. This was our first case of treating aHCM using a bidirectional approach. In Case 2 , extended myectomy was preferred because we considered that the removal of both the thin apex aneurysm and part of the septum was necessary, and we could secure the patient's postoperative LVEDV. A comparison of pre- and post-CT scans in both cases, showed increased LVEDV, especially in the first one.

Moreover, poor visibility caused considerable difficulty in the first case (Table 1). Therefore, we could not determine the correct direction or depth from the apex for the incision. Although this depends on the surgeon's skills and experience, adding a transaortic incision and using a finger as a guide from the LVOT can be helpful. Intraoperative TEE is also beneficial.

After a discussion with our team of cardiovascular surgeons and cardiologists, we reached a consensus to perform these procedures rather than provide medical treatment for the patients of the two cases. Consequently, we hope that the positive outcomes from these two cases will lead to improvements in extended myectomy.

Apical myectomies are rarely performed; however, there is a need to standardize this method. In Japan, heart transplantation for aHCM is not feasible because there are very few transplantation facilities. Heart transplantation is a longer procedure than extended myectomy. The latter can be challenging, but a detailed surgical procedure has been recently reported $[3,11-$ 13]. Almost half of the global aHCM cases occur in Asian countries; therefore, clinicians should gather sufficient surgical experience in extended myectomy.

\begin{abstract}
Abbreviations
AML: Anterior mitral leaflet; CT: Computed tomography; aHCM: Apical hypertrophic cardiomyopathy; ICD: Implantable cardioverter-defibrillator; LV: Left ventricular; LVEDV: Left ventricular end-diastolic volume; LVOTO: Left ventricular outflow tract obstruction; LVOT: Left ventricular outflow tract; LVOTS: Left ventricular outflow tract stenosis; SAM: Systolic anterior motion; SV: Stroke volume; TEE: Transesophageal echocardiography; TTE: Transthoracic echocardiography.
\end{abstract}

\section{Acknowledgements \\ None.}

\section{Authors' contributions}

DS performed data collection and wrote the manuscript. MS supported the writing of the manuscript. ST participated in the design of the study. All authors read and approved the final manuscript.

\section{Funding}

None.

Availability of data materials

All data generated or analyzed during this study are included in this published article. Data sharing is not applicable to this article as no datasets were generated or analyzed during the current study.

\section{Declarations}

\section{Ethics approval and consent to participate}

This was a case report and the requirement for an approval from the Institutional Review Board of Sakakibara Heart Institute was waived.

\section{Consent for publication}

The patients provided informed consent for the publication of this report and accompanying images.

\section{Competing interests}

The authors declare no competing interests.

\section{Author details}

${ }^{1}$ Department of Cardiovascular Surgery, Sakakibara Heart Institute, Tokyo, Japan. ${ }^{2}$ Cardiology, Sakakibara Heart Institute, Tokyo, Japan.

Received: 15 January 2021 Accepted: 19 December 2021

Published online: 30 December 2021 


\section{References}

1. Rogers PJ, Geib AJ, Cuthbert D, Wei G. Apical hypertrophic cardiomyopathy: a concerning electrocardiogram in the emergency department. J Emerg Med. 2018;54:867-70.

2. Sakamoto T, Tei C, Murayama M, Ichiyasu H, Hada Y. Giant T wave inversion as a manifestation of asymmetrical apical hypertrophy $(A A H)$ of the left ventricle: echocardiographic and ultrasono-cardiotomographic study. Jpn Heart J. 1976; 17:611-29.

3. Nguyen A, Schaff HV, Nishimura RA, Geske JB, Dearani JA, King KS, et al. Apical myectomy for patients with hypertrophic cardiomyopathy and advanced heart failure. J Thorac Cardiovasc Surg. 2019. https://doi.org/10. 1016/j.jtcvs.2020.08.118.

4. Chen X, Dong JZ, Du X, Wu JH, Yu RH, Long DY, et al. Long-term outcome of catheter ablation for atrial fibrillation in patients with apical hypertrophic cardiomyopathy. J Cardiovasc Electrophysiol. 2018;29:951-7.

5. Binder J, Ommen SR, Gersh BJ, Van Driest SL, Tajik AJ, Nishimura RA, et al. Echocardiography-guided genetic testing in hypertrophic cardiomyopathy: septal morphological features predict the presence of myofilament mutations. Mayo Clin Proc. 2006;81:459-67.

6. Moon J, Shim CY, Ha JW, Cho IJ, Kang MK, Yang WI, et al. Clinical and echocardiographic predictors of outcomes in patients with apical hypertrophic cardiomyopathy. Am J Cardiol. 2011;108:1614-9.

7. Hughes RK, Knott KD, Malcolmson J, Augusto JB, Mohiddin SA, Kellman P, et al. Apical hypertrophic cardiomyopathy: the variant less known. J Am Heart Assoc. 2020;9:e015294.

8. Hang D, Schaff HV, Ommen SR, Dearani JA, Nishimura RA. Combined transaortic and transapical approach to septal myectomy in patients with complex hypertrophic cardiomyopathy. J Thorac Cardiovasc Surg. 2018;155:2096-102.

9. Kotkar KD, Said SM, Schaff HV. Transapical approach for myectomy in hypertrophic cardiomyopathy. Ann Cardiothorac Surg. 2017;6:419-22.

10. Merrill WH, Friesinger GC, Graham TP Jr, Byrd BF III, Drinkwater DC Jr, Christian KG, et al. Long-lasting improvement after septal myectomy for hypertrophic obstructive cardiomyopathy. Ann Thorac Surg. 2000;69:1732-5.

11. Schaff HV, Said SM. Transaortic extended septal myectomy for hypertrophic cardiomyopathy. Oper Tech Thorac Cardiovasc Surg. 2012;17:238-50.

12. Schaff HV, Brown ML, Dearani JA, Abel MD, Ommen SR, Sorajja P, et al. Apical myectomy: a new surgical technique for management of severely symptomatic patients with apical hypertrophic cardiomyopathy. J Thorac Cardiovasc Surg. 2010;139:634-40.

13. Takayama H, Yu SN, Sorabella R, Leb J, Pulerwitz TC, Cooper C, et al. Virtual septal myectomy for preoperative planning in hypertrophic cardiomyopathy. J Thorac Cardiovasc Surg. 2019;158:455-63.

\section{Publisher's Note}

Springer Nature remains neutral with regard to jurisdictional claims in published maps and institutional affiliations.

Ready to submit your research? Choose BMC and benefit from:

- fast, convenient online submission

- thorough peer review by experienced researchers in your field

- rapid publication on acceptance

- support for research data, including large and complex data types

- gold Open Access which fosters wider collaboration and increased citations

- maximum visibility for your research: over $100 \mathrm{M}$ website views per year

At BMC, research is always in progress.

Learn more biomedcentral.com/submissions 